\title{
Cost benefits of low dose subcutaneous erythropoietin in patients with anaemia of end stage renal disease
}

\author{
Marion E Stevens, Geoffrey P Summerfield, Alan A Hall, Carol A Beck, Anthony J Harding, \\ J Rodney Cove-Smith, Andrew D Paterson
}

\begin{abstract}
Objective - To assess the cost benefits of low dose subcutaneous recombinant human erythropoietin in correcting the anaemia of end stage renal disease.

Design-Three year retrospective study.

Setting-Subregional nephrology service serving a mixed urban and rural population of 800000 .

Subjects -60 patients with symptoms of anaemic end stage renal disease treated with erythropoietin (43 receiving haemodialysis; 11 receiving continuous ambulatory peritoneal dialysis; two with predialysis end stage renal disease; four with failing renal transplants).
\end{abstract}

Main outcome measures-Costs and savings of achieving and maintaining a haemoglobin concentration of 85-105 $\mathrm{g} / \mathrm{l}$ with erythropoietin.

Results-All patients treated with erythropoietin achieved the target haemoglobin concentration at median induction doses of 97 (95\% confidence interval 95 to 108 ) units $/ \mathrm{kg} /$ week, and this was maintained with 79 ( 75 to 95$)$ units/ $/ \mathrm{kg} /$ week at an average annual cost per patient of $£ 2260$. Admissions related to anaemia were virtually eliminated (246 $v 1$ inpatient days for 12 months before and after starting erythropoietin). 54 patients required no blood transfusions after starting erythropoietin, and the total requirements fell from 230 to 21 units in the 12 months before and after starting erythropoietin. Iron stores were maintained with oral or intravenous iron. All patients reported increased wellbeing, appetite, and exercise capacity. Hypertension developed or worsened in 30 patients, resulting in hospital admissions in five patients, one of whom had seizures.

Conclusion-Low dose subcutaneous erythropoietin restores haemoglobin concentrations sufficiently to abolish blood transfusion requirements and reduce morbidity. The net cost of erythropoietin prescribed in this way ( $2260 /$ patient/year) was largely offset by savings in costs of hospital admis sions. The true annual cost to the NHS was around $£ 1200$ per patient.

\section{Introduction}

Erythropoietin has revolutionised the treatment of the anaemia of chronic renal failure. Recombinant human erythropoietin is now recognised as safe and effective treatment for the severe anaemia of end stage renal disease ${ }^{1-4}$ and the Renal Association, through the Department of Health, has drawn up criteria for its use.

The documented benefits in quality of life, ${ }^{67}$ exercise tolerance, ${ }^{6.9}$ and cardiovascular function ${ }^{7-9}$ have to be weighed against the financial implications of treating all patients with end stage renal disease who meet these criteria. The cost of this drug was initially so high that a considerable strain was placed on the already stretched budgets of renal units in the United Kingdom. ${ }^{1011}$

Newer techniques for administering the drug have, however, reduced this cost. These include using the subcutaneous rather than the intravenous route and aiming at haemoglobin concentrations of around $105 \mathrm{~g} / \mathrm{l}$ rather than attempting to reach normal concentrations. ${ }^{1213}$ Furthermore, to ensure that erythropoietin is effective at the minimum possible dose adequate iron stores must be maintained by oral or intravenous iron supplements. ${ }^{12}{ }^{13}$

We reviewed the effects of treatment with erythropoietin in all patients with end stage renal disease under the care of South Cleveland Hospital renal unit who fulfilled the Renal Association and Department of Health criteria. We examined the costs of treatment to assess potential savings from reduced need for blood transfusions and inpatient treatment as this encompasses a measure of quality of life not addressed by standard methods such as the Nottingham health profile and the Kind and Rosser scale for valuation of the state of illness. ${ }^{14}$ is

\section{Patients and methods}

South Cleveland Hospital renal unit serves a mixed urban and rural population of 800000 . In December 1990 there were 70 patients receiving hospital haemodialysis, 14 receiving home haemodialysis, and 35 continuous ambulatory peritoneal dialysis; 137 patients had functioning renal grafts. Patients were selected for erythropoietin treatment according to the following criteria: $(a)$ symptomatic anaemia rendering them unable to perform daily household, work, and leisure activities; $(b)$ repeated blood transfusions for symptomatic severe anaemia; $(c)$ haemoglobin related angina, unrelieved by maximal medical treatment; $(d)$ bilateral nephrectomy with symptomatic anaemia.

Patients were excluded from erythropoietin treatment if they had unstable or uncontrolled hypertension, evidence of inadequate dialysis, hyperkalaemia, epilepsy or a history of fits, or another cause of anaemia. Sixty patients 43 receiving long term maintenance haemodialysis, 11 receiving continuous ambulatory peritoneal dialysis, four patients with failing transplants, and two with predialysis end stage renal disease) met these criteria and were studied between June 1988 and May 1991. One anephric patient started erythropoietin one month after starting dialysis. All other patients dependent on dialysis had been stable on dialysis for at least three months.

Patients were studied from 12 months before to 12 months after the start of erythropoietin treatment or until death or renal transplantation. The variables with cost implications studied were total cost of erythropoietin prescribed and cost per patient per year; cost of administration of erythropoietin; cost of blood transfusion and its administration; cost of inpatient care, including that related to anaemia and side effects of erythropoietin; and cost of extra iron supplementation and monitoring.

Costs were calculated on the basis of the number of patient years at risk for all 60 patients over the 12 months before and after starting erythropoietin, taking as end points transplantation and death. Patients withdrawn from treatment were assessed for the full study period. The first five patients to receive erythropoietin

Correspondence to

Dr Stevens. 
were given 50 units $/ \mathrm{kg}$ intravenous erythropoietin three times a week as part of an international clinical trial. Subsequently, four further patients received 2000 units of subcutaneous erythropoietin twice a week. The other 51 patients were given initial doses of 2000 units three times a week. The dose in all patients was maintained or increased until a target haemoglobin concentration of around $100 \mathrm{~g} / \mathrm{l}$ (range 85-105) was achieved and then adjusted to the lowest dose necessary to maintain haemoglobin concentrations. Doses were adjusted by altering the interval between doses; multiples of 2000 units were used to reduce wastage.

Information on patients, serial serum ferritin concentrations, erythropoietin doses, and costs were obtained from the computer systems in the renal unit, district biochemistry department, and pharmacy. Retrospective details of all blood transfusions given were obtained from the data management system in the district blood transfusion laboratory. The cost of direct patient care and service overheads were obtained for inpatient care in a specialist nephrology ward in £/patient/day from 1989-90 Körner statistical returns held by the department of finance, South Tees Health Authority. The number of inpatient days was assessed, and the underlying problem necessitating admission reviewed from the case notes. Hospital admissions were regarded as due to anaemia when admission was directly attributable to the anaemia or its complications (such as angina) and not related to vascular or peritoneal access procedures, peritonitis or other acute infections, or thrombotic events. Patients were not admitted for blood transfusions, which were given during hospital dialysis sessions or as day cases.

Erythropoietin doses and changes in haemoglobin values are expressed as the median ( $95 \%$ confidence interval).

\section{Results}

We studied 60 patients ( 28 men) with a median age of 53 (range 19-75) years. For the 54 patients dependent on dialysis the median time spent on dialysis before erythropoietin was started was 18 (1-179) months. We obtained data for a full 12 months before starting erythropoietin treatment on all but four patients.

Fourteen patients had successful transplant operations within 12 months of starting erythropoietin, after an average of 27.5 weeks' erythropoietin treatment (range 5-51). Eight patients died while taking erythropoietin (four of sepsis, one of malignancy, one of heart failure, one of myocardial infarction during haemodialysis, and one had a sudden death associated with hyperkalaemia). Erythropoietin was not considered to have been an important factor in any of these deaths, and the percentage of deaths in this group of patients (13\%) compared favourably with that in the renal unit dialysis patients as a whole over the three years of the study $(17 \cdot 6 \%(19 / 109)$ in $1988 ; 23.8 \%(25 / 105)$ in $1989 ; 16.2 \%(18 / 111)$ in 1990$)$. The total study amounted to 56.8 patient years before erythropoietin and 46.3 patient years after starting treatment.

Erythropoietin was discontinued in three patients within seven days; one patient had a mild cerebrovascular accident, one received a renal transplant, and one requested withdrawal. Erythropoietin was withdrawn from six further patients: from two at their own request and in the absence of complications; from one with a failing transplant, in whom erythropoietin could be withdrawn after correcting haemoglobin concentration; from one after a cerebrovascular accident in the absence of uncontrolled hypertension; and from two with uncontrolled hypertension, complicated in one case by fits.

After starting erythropoietin 30 patients required

\section{Yearly costs of erythropoietin in 60 patients with anaemia associated with end stage renal disease}

Total cost of erythropoietin prescribed June 1988-December 1990:

From patient clinical and computer records

From pharmacy department computer records

$£ 105331$

$£ 106000$

Total cost of erythropoietin for all patients for first 12 months of treatment

Number of patient years at risk

Cost of erythropoietin per patient per year

Cost of administering erythropoietin

(including insulin syringes, extra blood tests, blood pressure monitoring equipment) per patient per year

Total cost of erythropoietin per patient per year

increased treatment for hypertension. In five, hypertension was severe enough to necessitate admission to hospital for a total of 15 days, and erythropoietin was withdrawn in two patients, one of whom had fits as a result of hypertensive encephalopathy. A full recovery ensued but erythropoietin was not restarted.

Forty patients administered erythropoietin themselves and monitored their own blood pressure, with minimal training required. One patient receiving home dialysis was given erythropoietin by her husband; two patients at home receiving continuous ambulatory peritoneal dialysis, both of whom had insulin dependent diabetes, received erythropoietin from the district nurse, who was already making domiciliary visits to give insulin injections twice daily. The other 17, all receiving haemodialysis in hospital, had erythropoietin injections from haemodialysis nursing staff at the time of dialysis.

Intravenous erythropoietin at 150 units $/ \mathrm{kg} /$ week (five patients) increased haemoglobin concentrations, which rose by a median of 11 (95\% confidence interva 5 to 17$) \mathrm{g} / \mathrm{l}$ at one month and by 26 (11 to 41$) \mathrm{g} / \mathrm{l}$ at three months. Subcutaneous low dose erythropoietin ( 55 patients) increased haemoglobin concentrations by 12 ( 1 to 26 ) $\mathrm{g} / \mathrm{l}$ at one month, by 20 (5 to 36 ) g/l at three months, and by $23(7$ to 40$) \mathrm{g} / \mathrm{l}$ at 12 months. The target haemoglobin concentration was achieved by three months (47 patients) or six months (six patients) unless transplantation, death, or withdrawal from the study supervened (seven patients).

Induction doses of 33-162 units $/ \mathrm{kg} /$ week, median 97 (95 to 108 ) units $/ \mathrm{kg} /$ week, were sufficient to achieve target haemoglobin concentrations, which were then maintained with doses of 19-251 units $/ \mathrm{kg} /$ week, median 79 (75 to 95 ) units $/ \mathrm{kg} /$ week at six and 12 months. At the target haemoglobin concentration all patients reported a sustained increase in exercise tolerance, appetite, and general wellbeing.

The cost of treatment with erythropoietin ( $\$ 2210 /$ patient/year) calculated from patients' clinical and computer records accurately matched that calculated independently from computerised pharmacy records (box), and when administration costs of erythropoietin were taken into account the total cost of erythropoietin treatment increased to $£ 2260$ per patient per year.

Six patients who developed iron overload at the beginning of erythropoietin treatment showed a fall in serum ferritin concentration from a raised concentration. None of the patients was iron deficient when erythropoietin was begun, but 28 developed biochemical evidence of iron depletion during erythropoietin treatment (serum ferritin $<100 \mu \mathrm{g} / \mathrm{l}$ ) and 
TABLE I-Requirements for blood transfusions in the 12 months before and after starting erythropoietin treatment

\begin{tabular}{ccc}
\hline & $\begin{array}{c}\text { No of } \\
\text { routine } \\
\text { blood }\end{array}$ & $\begin{array}{c}\text { No of } \\
\text { transfusions } \\
\text { for specific } \\
\text { Months }\end{array}$ \\
$\begin{array}{cc}\text { transfusions } \\
\text { events }\end{array}$ \\
\hline 12 & 11 & \\
11 & 10 & \\
10 & 7 & \\
9 & 8 & \\
8 & 22 & 6 \\
7 & 27 & 10 \\
6 & 18 & \\
5 & 17 & \\
4 & 21 & \\
3 & 27 & \\
2 & 20 & \\
1 & 42 & 16 \\
Erythropoietin & \\
started & 3 & \\
1 & 3 & \\
2 & 3 & \\
3 & 5 & \\
4 & 1 & \\
5 & 1 & \\
6 & & \\
7 & 2 & \\
8 & & \\
9 & & \\
10 & & \\
11 & 2 & \\
12 & 4 & \\
\hline & & \\
\hline
\end{tabular}

required additional or increasing amounts of oral iron; 18 patients who were unable to tolerate oral iron in doses sufficient to correct serum ferritin concentrations or maintain them above $100 \mu \mathrm{g} / \mathrm{l}$ received iron dextran infusions on 53 occasions at the time of dialysis $(500 \mathrm{mg}$ elemental iron in $10 \mathrm{ml}$; cost $£ 2.70$ per ampoule). There were no untoward side effects. Total cost of iron dextran was $£ 143.10$ or $£ 3.09$ per patient per year. The costs of oral iron supplementation and monitoring iron status were negligible, as were the costs of other changes in treatment such as increased use of hypotensive drugs.

The sustained improvement in haemoglobin concentration occurred with a large fall in requirements for blood transfusion (table I) from a total of 230 units in the 12 months before starting erythropoietin treatment to 21 units in the 12 months after starting. Fifty four patients required no further transfusion after starting erythropoietin. The cost savings for blood transfusion per patient per year were $£ 146$ (table II).

In the pretreatment period patients were hospitalised for 246 days $(4 \cdot 33$ days/patient/year) for problems related to anaemia. After starting on erythropoietin anaemia was responsible for one inpatient day and complications of erythropoietin treatment for 15 days $(0.35$ days/patient/year). Standard Körner costs of inpatient treatment in a specialist nephrology ward in South Tees were $£ 225.05$ per patient per day. If admissions related to anaemia are offset against admissions for complications the cost savings of treatment with erythropoietin amount to $£ 889$ per patient per year (table II).

TABLE II -Cost benefits of treatment with erythropoietin for anaemia of end stage renal disease

\begin{tabular}{|c|c|c|c|}
\hline & $\begin{array}{l}\text { Before } \\
\text { erythropoietin }\end{array}$ & $\begin{array}{c}\text { After } \\
\text { erythropoietin }\end{array}$ & $\begin{array}{c}\text { Net } \\
\text { saving }\end{array}$ \\
\hline Patient years of study & $56 \cdot 8$ & $46 \cdot 3$ & \\
\hline \multicolumn{4}{|l|}{$\begin{array}{l}\text { Transfusion costs } \\
\text { (cost per unit } £ 40.70 \text { ): }\end{array}$} \\
\hline Total No of units required & 230 & 21 & \\
\hline Units/patient/year & $4 \cdot 1$ & 0.45 & \\
\hline Costs/patient/year $(\mathfrak{L})$ & $164 \cdot 8$ & $18 \cdot 46$ & $146 \cdot 35$ \\
\hline \multicolumn{4}{|l|}{$\begin{array}{l}\text { Costs of admissions to hospital } \\
\text { (specialty in patient cost/day } \\
£ 225.05 \text { ): }\end{array}$} \\
\hline $\begin{array}{l}\text { No of days' admission } \\
\text { related to anaemia }\end{array}$ & 246 & 1 & \\
\hline $\begin{array}{l}\text { No of days for complications } \\
\text { of erythropoietin: }\end{array}$ & & 15 & \\
\hline Days/patient/year & $4 \cdot 3$ & 0.35 & \\
\hline Costs/patient/year (£) & 967.71 & 78.77 & $888 \cdot 94$ \\
\hline
\end{tabular}

Net saving per patient year $£ 1035 \cdot 29$

One unit of blood costs $£ 35 \cdot 80$ per pack plus $£ 4.90$ administration cost.

Admissions to hospital for all causes totalled 1042 inpatient days in the pretreatment period (18 days/ patient/year) and 560 days in the treatment period (12 days/patient/year). If these differences are discounted the final cost analysis of low dose subcutaneous erythropoietin shows a net cost to the NHS of $£ 1228$ per patient per year (table III).

TABLE III-Cost analysis of erythropoietin treatment in 60 patients with end stage renal disease over 12 months before and after treatment with erythropoietin:

\begin{tabular}{|c|c|c|}
\hline & $\mathfrak{f} / \mathrm{Pa}$ & $\begin{array}{l}\text { ient/ } \\
\text { ar }\end{array}$ \\
\hline \multirow{7}{*}{$\begin{array}{l}\text { Costs } \\
\text { Erythropoietin } \\
\text { Iron infusions } \\
\text { Savings } \\
\text { Blood transfusion } \\
\text { Hospital admission } \\
\text { for anaeamia }\end{array}$} & \multirow{2}{*}{\multicolumn{2}{|c|}{$2260 \quad 2263$}} \\
\hline & & \\
\hline & 3 & \\
\hline & \multicolumn{2}{|r|}{1035} \\
\hline & \multicolumn{2}{|l|}{146} \\
\hline & \multirow{2}{*}{\multicolumn{2}{|c|}{889}} \\
\hline & & \\
\hline Net cost to NHS & & 1228 \\
\hline
\end{tabular}

\section{Discussion}

We have shown that substantial hidden savings result from using erythropoietin to treat anaemia in patients with end stage renal disease. These savings largely offset the high purchase price of the drug. Decreases in costs from the fall in blood transfusion requirements are predictable ${ }^{14}$ and are confirmed by this study. They are, however, overshadowed by the considerable reduction in time spent in hospital resulting from the reduced morbidity after treatment with erythropoietin.

In our analysis of costs we identified savings only in hospital admissions related to anaemia or its complications. There was a further substantial reduction in admissions for other causes, which would also reduce the cost of erythropoietin treatment. As these apparent savings are not directly attributable to the physiological effects of erythropoietin (that is, relieving anaemia) they have not been included in our formal comparisons of costs.

We have shown that an acceptable target haemoglobin concentration can be achieved with considerably lower doses of erythropoietin given subcutaneously than the manufacturers recommend for intravenous administration and at a lower dose than many previous reports. ${ }^{1-46-9} 1116-19$

The subcutaneous route has the advantage of allowing safe self administration of erythropoietin at home. ${ }^{18} 19$ The low dose subcutaneous schedule allowed us to provide erythropoietin for all patients satisfying our criteria for treatment at an annual drug cost of $£ 2260$ per patient, less than half the previously published annual cost of over $£ 5000 .^{1114}$ We have minimised wastage by altering the frequency of administration of whole phials rather than the size of dose, and we emphasise the importance of maintaining iron stores not only at the start of treatment but also after the initial rise in haemoglobin concentration.

Erythropoietin was probably largely responsible for the reduction in rates of admission to hospital. It remains our practice, however, not to admit patients solely for "top up" transfusions, and these are given either during outpatient haemodialysis treatment or as a day case to patients receiving continuous ambulatory peritoneal dialysis or to those not yet receiving dialysis. This practice did not change during the study. Less severely anaemic patients may recover more quickly from intercurrent illness and avoid admission or be discharged home earlier. Anaemia itself may be an important precipitating factor for conditions such as angina which require admission especially in elderly patients.

Although we did not formally assess quality of life, few who have received erythropoietin and fewer who have prescribed it doubt its beneficial effects on wellbeing. Formal studies have been carried out confirming this. ${ }^{6}$ Erythropoietin was of particular value for the increasing numbers of elderly dialysis patients who tolerate anaemia poorly. One patient with chronic chest disease and angina was able to discontinue domiciliary oxygen and take increasing amounts of exercise for the first time since starting haemodialysis. Many of our elderly dialysis patients, far from being dependent invalids themselves, were often the sole carers for other elderly disabled spouses or relatives. Any improvement in their exercise capacity, or reduction in hospital admissions, enabled them to sustain an active carer's role and maintain an independent existence.

The savings from the reduction in transfusion requirements are secondary to the therapeutic advantages of an alternative treatment for the anaemia of end stage renal disease. Frequent blood transfusion increases the exposure of patients to the risks of iron overload, virus transfer, and sensitisation to transplantation antigens. Transplantation remains the most cost effective long term mode of renal replacement therapy as well as restoring a source of endogenous erythropoietin. Avoiding sensitisation by giving erythropoietin may prove to be an important way of increasing the chance of finding a suitable donor kidney. Our study shows that although erythropoietin is a relatively expensive form of treatment, its use does not add greatly to the total cost of the treatment of end stage renal disease, the net cost per patient being just over $£ 1200$ a year. In view of the documented enhancement in quality of life produced by erythropoietin we propose that the drug should become part of the 
standard treatment of kidney failure and that proper funding should be made available through the NHS.

1 Winearls CG, Oliver DO, Pippard MJ, Reid G, Downing MR, Cotes PM. Effect of human erythropoietin derived from recombinant DNA on the anaemia of patients maintained by chronic haemodialysis. Lancet 1986;ii $117-8$.

2 Eschbach JW, Egne JC, Downing MR, Browne JK, Adamson JW. Correction of the anemia of end-stage renal disease with recombinant human erythropoietin. NEngl f Med 1987;316:73-8.

3 Sinai-Trieman L, Salusky IB, Fine RN. Use of subcutaneous recombinan human erythropoietin in children undergoing continuous cycling peritoneal human erythropoietin in children

4 Eschbach JW, Kelly MR, Halet NR, Abells RI, Adamson M, Adamson JW. Treatment of the anemia of progressive renal failure with recombinan
(a) human erythropoietin. $N$ Engl F Med 1989;321:158-63.

5 Executive Committee of the Renal Association. Recommendations for the use of recombinant human erythropoietin in patients with renal failure. London: HMSO, 1990. (Department of Health Circular PL/CO (90).)

6 Canadian Erythropoietin Study Group. Association between recombinan human erythropoietin and quality of life and exercise capacity of patient receiving haemodialysis. BMF 1990;300:573-8.

7 Casati S, Passerini P, Campise MR. Benefits and risks of protracted treatment with human recombinant erythropoietin in patients having haemodialysis. BMF 1987;295: 1017-20.

8 MacDougall IC, Lewis NP, Saunders MJ. Long term cardio-respiratory effects of amelioration of renal anaemia by erythropoietin. Lancet 1990;335: $489-93$.

9 Eschbach JW, Adamson JW. Recombinant erythropoietin. Implications for nephrology. Am f Kidney Dis 1988;11:203-9.

10 Gabriel R. Picking up the tab for erythropoietin. BMf 1991;302:248-9.

11 Taylor J, Henderson IS, Mactier RA, Stewart WK. Erythropoietin with drawal. BM7 1991;302:272-3.

12 Macdougall IC, Hulton RD, Cavill I, Coles GA, Williams JD. Treating renal anaemia with recombinant human erythropoietin: practical guidelines and a anaemia with recombinant human erythropo

13 Pollok M, Bommer J, Gurland HJ, Koch KM, Schoeppe W, Scigalla P, et al. Effects of recombinant human erythropoietin treatment in endstage renal Effects of recombinant human erythropoietin tre
failure patients. Contrib Nephrol 1989;76:201-11.

14 Leese B, Hutton J, Maynard A. The costs and benefits of the use of erythropoietin in the treatment of anaemia arising from chronic renal failure: a European study. York: Centre for Health Economics, University of York, 1991

15 Rosser R, Kind P. A scale of valuation of state of illness. Int $\mathcal{f}$ Epidemiol 1978;7:347-58.

16 Eschbach JW. The anemia of chronic renal failure: pathophysiology and the effects of recombinant erythropoietin. Kidney Int 1989;35:134-48.

17 Winearls CG. Erythropoietin. Nephrol Dial Transplant 1989;4:323-6.

18 Bommer J, Ritz E, Weinrich T, Bommer G, Ziegler T. Subcutaneous erythropoietin. Lancet 1988;ii:406.

19 Stevens JM, Strong CA, Oliver DO, Winearls CG, Cotes PM. Subcutaneous erythropoietin and peritoneal dialysis. Lancet 1989;i:1388-9.

Mysterious slapped face rash at holiday centre

\section{J Gunnell}

Abstract

Objective-To discover the cause of an outbreak of facial rash in a holiday centre.

Design-Questionnaire survey of those with rash; analysis of samples of linen.

Setting-Holiday centre in south west England.

Patients -98 holidaymakers presenting to the first aid post with a facial rash.

Intervention-Replacement of bed linen with new linen in selected parts of the site.

Results-The attack rate was $7 \cdot 0-14 \cdot 2 / 1000$ for most accommodation areas in the centre, but in one accommodation area the rate was zero. The $\mathrm{pH}$ of rinse water from sheets varied from $7 \cdot 4$ to 9.0. Those parts of the accommodation provided with new linen had zero attack rates.

Conclusion-The facial rash resulted from irritation from washing powder retained owing to insufficient rinsing during laundering. Modifications to the rinsing process led to a gradual disappearance of the rash.

\section{Introduction}

In March 1991 Somerset Health Authority's department of public health was informed by the local district council's department of environmental health of a mysterious "slapped face" rash at one of the holiday sites in its district. Investigations into the cause of the rash had been inconclusive; an infective cause, parvovirus infection (erythema infectiosum or slapped cheek disease), was suggested by local general practitioners and a dermatologist on the basis of appearance of the rash. Subsequent virological test results were negative and the epidemiology of the outbreak did not correspond to known infectious agents. No cases were reported in the local town by general practitioners. An allergen or irritant was thought the most likely cause for the rash, and a questionnaire survey was undertaken to identify the cause. The rash itself varied in severity from mild localised erythema on the cheeks alone to a more generalised erythema extending from the cheeks to the upper neck and ears. There was no scaling, weeping, or petechiae. The more severe rashes were pruritic and were slightly raised with an irregular margin. No pigmentation was left when the rash improved.

The centre at which the outbreak occurred can accommodate over 9500 guests. Some of the six main accommodation areas are self catering and others accommodate guests on half board. Soap and towels are not provided. The self catering accommodation is serviced by staff from the centre and outside contract staff before its occupation and thereafter by the customer. Half board accommodation is serviced daily by centre staff. Sheets and pillow cases in most rooms are provided by the centre. The site water supply is separate from that of the town; the centre obtains most of its food from a national supply depot, but some fresh food is obtained locally.

\section{Methods}

Cases were defined as all patients attending the first aid post complaining of a facial rash characterised by bright red cheeks or neck, or both, appearing as if the person had been slapped in the face. Cases were recorded by staff (registered general nurses and local general practitioners) at the first aid post.

Case notes were reviewed to determine the speed of onset of rash, the attack rate, and other characteristics of the illness. A register of all patients with rash was kept, recording name, age, chalet number, site of rash and associated features, date and time of arrival on site, and time of onset of rash.

Consecutive patients between 26 March and 6 April were surveyed by questionnaire to collect details of the use of the swimming pools, baths, and showers and source of food and drink consumed in the 24 hours before they attended for first aid. Serological testing for parvovirus and full blood counts were performed in several patients.

A controlled trial was performed. The site management purchased 250 new sheets and pillow cases and placed these in selected chalets. The new linen was then cleaned at a different laundry and reused for the next intake of guests in the same chalets. Results in the chalets with new sheets were compared with those in the other chalets.

The county analyst measured the $\mathrm{pH}$ of fixed 